\title{
ACUTE LIMB ISCHEMIA IN CRITICALLY ILL COVID-19 PATIENTS: A CASE SERIES AND LITERATURE REVIEW
}

Soumaya Touzani, Fatima Zahra Haddari, Abderrahim El Bouazzaoui, Nawfal Houari, Brahim Boukatta, Nabil Kanjaa COVID-19 ICU, Anesthesiology and Intensive Care Department A4, Hassan II ${ }^{\mathrm{d}}$ University Hospital, Fez, Morocco Faculty of Medicine and Pharmacy, Sidi Mohammed Ben Abdellah University, Fez, Morocco

\section{ABSTRACT}

Background: The vascular burden increased by COVID-19 infection and including acute limb ischemia (ALI) quickly emerged as a major medical challenge with devastating consequences such as limb loss, multiorgan dysfunction and death. We report a case series of COVID-19 infection associated with ALI to raise awareness and knowledge towards this life-threatening association.

Methods: COVIDS-19 patients with acute limb ischemia (ALI) managed in a Moroccan 14 beds COVID-19 ICU between March 2020 and January 2021, were reviewed. Data collected included demographics, clinical presentation, treatments and outcomes.

Results: Over the 10-month period, our ICU cared for 407 hospitalized patients with confirmed COVID-19. A total of 6 COVID-19 patients with ALI were identified. The mean age was 61 years $(52-70)$ and 5 were men. The most common preexisting condition was diabetes (50\%). The mean CRP level was $219 \mathrm{mg} / \mathrm{L}$. Five patients had thrombus in multiple locations. No concomitant deep vein thrombosis was identified. Four patients presented with signs of acute arterial ischemia with or without respiratory symptoms and were subsequently diagnosed with COVID-19. The remaining two patients developed ischemia during hospitalization. Mean SOFA score was 5 (2 9). Respiratory support, corticosteroids and heparin therapies were used in all patients. Intubation and vasopressors were required in four patients. Revascularization was performed in five patients and reintervention was necessary in three cases. Four patients died in the ICU while two were successfully discharged.

Conclusion: ALI in COVID-19 patients is a challenging life-threatening vascular emergency that requires appropriate multidisciplinary management (intensivists, anesthesiologists, vascular surgeons and interventionists, radiologists, haematologists...) and further studies focused on anticoagulation.

Keywords: Acute Limb ischemia; coagulopathy; SARS-CoV-2; Thrombosis.

\section{Corresponding Author:}

Soumaya Touzani, MD

Affiliation: COVID-19 ICU, Anesthesiology and Intensive Care Department A4, Hassan IId University

Hospital, Fez, Morocco.

E-mail: touzani.soumaya@gmail.com

Copyright (c) 2012- 2021 Soumaya Touzani, et al. This is an open access article published under Creative Commons Attribution -Non Commercial- No Derives 4.0 International Public License (CC BY-NC-ND). This license allows others to download the articles and share them with others as long as they credit you, but they can't change them in any way or use them commercially.

doi: 10.46327/msrjg.1.000000000000----

*****Published in February 2021.

doi url: https://doi.org/10.46327/msrjg

\section{INTRODUCTION}

Coronavirus Disease (COVID-19) is no longer considered an infectious lung disease with a traditional ARDS (Acute Respiratory Distress Syndrome) but rather a convergence of vascular dysfunction, thrombosis, and dysregulated inflammation, that can lead to multi-organ failure and death $\left[\begin{array}{ll}1, & 2\end{array}\right]$ COVID-19 induced hypercoagulability is linked to a significant increasing risk of arterial and venous thrombosis [3, 4]. The vascular burden increased by COVID-19 infection and including acute limb ischemia (ALI) quickly emerged as a major medical challenge with devastating consequences such as limb loss, premature intubation, multiorgan dysfunction and death [5]. Bellosta et al reported an increasing incidence of ALI during the pandemic peak (16.3\% versus a baseline rate of $1.8 \%$ in the region study) and poorer surgical results due to the associated acquired hypercoagulability [6]. We report a case series of COVID-19 infection associated with ALI since awareness and knowledge of this lifethreatening association may improve early clinical identification and appropriate management. 


\section{METHODS}

This is a single center retrospective study conducted in a Moroccan 14 beds COVID-19 ICU over the period from March 24, 2020 to January $1^{\text {st }}$, 2021. All patients infected with COVID-19 and presenting acute limb ischemia (ALI) were included. The diagnosis of COVID-19 was based on real-time polymerase chain reaction (rt-PCR) of nasopharyngeal swab or serological blood test and/or chest CT scan. ALI was assessed by the vascular surgery team of our tertiary university hospital. Data collected included demographics, co-morbidities, clinical presentation, treatments and outcomes.

\section{RESULTS}

Throughout the 10-month study period, our unit cared for $\mathbf{4 0 7}$ hospitalized patients with confirmed COVID-19 infection. A total of 6 COVID-19 patients with ALI were identified. The mean age was 61 years (range $52-70$ ) and 5 were men. Four of our patients had co morbidities and were at risk of atherosclerosis while the other two were active with no co morbidities. The most common preexisting condition was diabetes (50\%). Four patients presented with signs of acute arterial ischemia with few or no respiratory symptoms and were subsequently diagnosed with COVID-19. The two remaining patients developed limb ischemia within 2 and 5 days following hospitalization. The mean
CRP level was $219 \mathrm{mg} / \mathrm{L}$. Computed tomography angiogram was diagnostic in five patients while one patient was too unstable for transport to imaging. The diagnosis in this latter case was based on clinical signs of acute ischemia. The lower extremity was affected in all our patients and thrombosis of large (aorta, iliac) and medium-sized (superficial/deep femoral, popliteal) arteries were the most commonly found. Four patients had multi-located arterial thrombi and no coexisting deep vein thrombosis was detected. Mean SOFA score was 5 (Range 2 -9). Respiratory support, corticosteroids and heparin therapies were used in all patients. Intubation and vasopressors were required in four patients. One patient was deemed too unstable for surgical intervention. Revascularization surgeries were performed in five patients under general or regional anesthesia as required by the patients and reintervention was necessary in three cases. Out of the five operated patients, three received open thrombectomy, one received open thrombectomy over two interventions and one bypass surgery, and one received endovascular thrombectomy, open thrombectomy, bypass surgery and secondary amputation over four interventions. Four patients died in the ICU while two were successfully discharged. Table I summarizes characteristics, diagnosis, management and outcomes of our patients.

Table I: Summary of patient characteristics, diagnosis, management and outcomes in our case series.

\begin{tabular}{|c|c|c|c|c|c|c|}
\hline Variables & Patient 1 & Patient 2 & Patient 3 & Patient 4 & Patient 5 & Patient 6 \\
\hline Age (year old), gender & 70 , male & 63 , female & 56 , male & 60 , male & 52 , male & 69 , male \\
\hline Co-morbidities & 0 & $\begin{array}{c}\text { Hypertension } \\
\text { Diabetes } \\
\text { Coronary disease } \\
\text { Hyperthyroidism }\end{array}$ & Diabetes & 0 & $\begin{array}{c}\text { Diabetes } \\
\text { Active smoking } \\
\text { Intermittent } \\
\text { claudication }\end{array}$ & $\begin{array}{l}\text { Active smoking } \\
\text { Intermittent } \\
\text { claudication }\end{array}$ \\
\hline $\begin{array}{l}\text { Charlson Comorbidity } \\
\text { Index }\end{array}$ & 3 & 4 & 2 & 3 & 4 & 3 \\
\hline $\begin{array}{l}\text { Usual antithrombotic } \\
\text { therapy }\end{array}$ & No & $\begin{array}{c}\text { Aspirin } 75 \mathrm{mg} / \text { day } \\
\text { Curative } \\
\text { anticoagulation }\end{array}$ & No & No & No & No \\
\hline $\begin{array}{l}\text { Antithrombotic therapy at } \\
\text { time of arterial event }\end{array}$ & $\begin{array}{c}\text { Curative } \\
\text { anticoagulation }\end{array}$ & $\begin{array}{c}\text { Curative } \\
\text { anticoagulation }\end{array}$ & No & No & No & No \\
\hline $\begin{array}{l}\text { Symptoms on hospital } \\
\text { admission }\end{array}$ & Respiratory & Respiratory & $\begin{array}{c}\text { Respiratory + } \\
\text { Acute right } \\
\text { lumb ischemia }\end{array}$ & $\begin{array}{l}\text { Respiratory }+ \\
\text { Lumb Ischemia }\end{array}$ & Lumb Ischemia & $\begin{array}{c}\text { Respiratory+ Lumb } \\
\text { Ischemia }\end{array}$ \\
\hline
\end{tabular}




\section{COVID-19 infection}

Time to hospital consultation

(days)

Clinical

presentation

Severe ARDS

Severe ARDS

Severe ARDS

Severe ARDS

NA

ARDS

RT-PCR

Negative

Negative

Positive

Positive

Positive

Positive

IgG Serology

Positive

Positive

NA

NA

Positive

NA

Chest CT scan

Damage $>55 \%$

Damage $75 \%$

Damage $>75 \%$

Damage $\geq 75 \%$

Bacterial-type condensation + No PE

\section{Arterial ischemia event}

Days COVID

onset to

thrombotic event

Symptoms

CT angiography

Treatment

Medical

\section{Medical + embolectomy \\ Descending thoracic aorta: Unstable ulcerated atheroma plaque \\ Left: popliteal + internal iliac arteries occlusion \\ Right: deep femoral artery occlusion}

No

\section{Acute left lumb} ischemia

Acute bilateral

lumb ischemia

Bilateral

primitive iliac

arteries subtotal stenosis

Left: Tibioperoneal trunk total stenosis

Right: internal iliac artery subtotal stenosis $+\quad$ popliteal artery and tibioperoneal trunk total stenosis

$$
\begin{gathered}
\text { Medical + } \\
\text { embolectomy }
\end{gathered}
$$

$$
\text { No }
$$$$
1
$$
artery
Medical + embolectomy/ Bypass

Reocclusion
0
Interventions

Anesthesia

Spinal
Total occlusion of the left popliteal

$$
\text { popliteal arteries }
$$

\section{Acute right lumb} ischemia

Occlusion of the right primitive iliac and

$$
\text { Medical + }
$$
embolectomy/ Bypass/ Amputation

Reocclusion
Acute bilateral lumb ischemia
Sub-renal aorta: atheroma

Superior mesenteric artery: Subtotal occlusion Left : primitive iliac and common femoral arteries occlusion Right: common femoral artery occlusion

Medical + embolectomy

Hematoma

2
3

4

General

No

No

No

No

No 


\section{Severity assessment}

$\begin{array}{lcccccc}\text { Shock } & \text { Yes } & \text { No } & \text { No } & \text { Yes } & \text { Yes } & \text { Yes } \\ \begin{array}{l}\text { Respiratory } \\ \text { failure }\end{array} & \text { Yes } & \text { Yes } & \text { Yes } & \text { Yes } & \text { Yes } & \text { Yes } \\ \text { SOFA } & 7 & 2 & 4 & 4 & 9 & 8 \\ \text { Lee Criteria* } & 3 / 6 & 2 / 6 & 1 / 6 & 1 / 6 & 2 / 6 & 1 / 6\end{array}$

\section{Blood parameters}

Creatinine, $\mathrm{mg} / \mathrm{l}$

(Range 8 - 14,40)

$\mathrm{WBC}, / \mathrm{mm} 3$

C-reactive

protein, mg/l (NR

$0-5$ )

256

115

200

242

319

CPK, IU/1 (NR 0 -

171)

63

877

429

451

2396

4803

LDH, IU/l (NR 0 -

248)

Platelets, $/ \mathrm{mm}^{3}$

$$
435000
$$

583000

270000

400000

56000

193000

Prothrombin Time

/ INR

D-dimer ng/mL

(NR 0 - 500)

Ferritin $\mu \mathrm{g} / \mathrm{l}(\mathrm{NR}$

$20-300$ )

900

3430

2880

983

1164

Troponin, ng/ml

(NR 0.00 - 0.08)

0.025

0

0.007

0.018

0.016

\begin{tabular}{|c|c|c|c|c|c|c|}
\hline Organ support therapies & $\begin{array}{c}\text { Intubation } \\
\text { Vasopressors }\end{array}$ & $\begin{array}{l}\text { High flow oxygen } \\
\text { therapy }\end{array}$ & $\begin{array}{l}\text { HFNC, NIV, } \\
\text { Prone }\end{array}$ & $\begin{array}{c}\text { Intubation } \\
\text { Vasopressors }\end{array}$ & $\begin{array}{c}\text { Intubation } \\
\text { Vasopressors }\end{array}$ & $\begin{array}{c}\text { Intubation } \\
\text { Vasopressors }\end{array}$ \\
\hline ICU stay (days) & 5 & 13 & 14 & 13 & 19 & 11 \\
\hline Outcome & $\begin{array}{c}\text { Death } \\
\text { Cardiogenic } \\
\text { shock }\end{array}$ & $\begin{array}{c}\text { Hospital discharge } 7 \\
\text { days after ICU } \\
\text { discharge }\end{array}$ & $\begin{array}{c}\text { Hospital } \\
\text { discharge } 48 \\
\text { hours after ICU } \\
\text { discharge }\end{array}$ & $\begin{array}{l}\text { Death } \\
\text { MOF }\end{array}$ & $\begin{array}{l}\text { Death } \\
\text { MOF }\end{array}$ & $\begin{array}{l}\text { Death } \\
\text { MOF }\end{array}$ \\
\hline
\end{tabular}

ARDS: Acute Respiratory Distress Syndrom $\mathrm{PaO}_{2} / \mathrm{FiO}_{2} \leq 300$; MOF: Multiple Organ Failure; NA: Not Applicable; NR: Normal Range; PE: Pulmonary Embolism; RT-PCR: Real Time Polymerase chain reaction; SOFA: Sequential Organ Failure Assessment; WBC: White Blood Cell Count. *Lee criteria: High risk surgery; coronary artery disease; congestive heart failure; cerebrovascular disease; diabetes mellitus on insulin; serum creatinine $>2 \mathrm{mg} / \mathrm{D}$ 


\section{DISCUSSION}

Despite anticoagulation, a high number of critically ill COVID-19 patients developed life-threatening thrombotic complications [3, 4], which raised questions about the unique physiopathology of COVID-19. Findings suggest that COVID-19 may predispose to both venous and arterial thromboembolism due to excessive inflammation, cytokine release, endothelial dysfunction, immobilization, hypoxia, and diffuse intravascular coagulation [2]. As a consequence of the COVID-19 induced coagulopathy, ALI emerged as a new crisis during the current pandemic as cases were constantly reported worldwide, and even among nonatherosclerotic COVID-19 patients [6 - 21]. As data result from case series and case reports, the incidence is not well studied and widely variable ranging from $0.3 \%$ [22] to $16.3 \%$ [6]. In the Italian observational study, Bellosta and al concluded that COVID-19 infection might increase the incidence of ALI (16.3\% during the pandemic peak versus a baseline rate of $1.8 \%$ in the region study) and be associated with poorer surgical results due to the induced hypercoagulability [6]. The incidence may be higher among critically ill patients as they are highly hypoxemic and inflammatory and because of immobilization. Within 10 months and among the 407 COVID-19 patients admitted to our unit, we provided care for six COVID-19 patients with acute limb ischemia. ALI typically occurs in hospitalized patients with severe COVID-19 within five to seven days after respiratory decompensation but can also affects patients with mild COVID-19 ALI [6, 22 24]. Moreover, it can be the sole clinical manifestation of COVID-19 [25, 26] as in the case of our patient 5 (Table I) or occur following recovery [27, 28]. ALI can develop in COVID-19 patients with no usual risk factors such as older age, obesity, and cardiovascular co morbidities and even when receiving thromboprophylaxis [6, 22 - 24]. The thrombosis of large and medium size vessels of the lower extremity [6, 22 - 24] is more commonly reported than the upper limb [29 -31] while thrombosis of small vessels can be related to vasopressors administration [32]. Thrombosis of prior vascular reconstruction involving stents and bypass grafts have also been reported [33]. Our findings are consistent with the reported clinical features above. COVID-19 induced hypercoagulability is likely related to an inflammatory cascade that leads to an endothelial thrombo- inflammatory syndrome through cytokine storm, complement activation, and endotheliitis. The virus itself may possibly activate the coagulation cascade through its receptors (angiotensinconverting enzyme 2) on vascular muscle and endothelial cells membrans $[2,34]$. Increasing D- dimer and inflammatory biomarkers such as Creactive protein, leukocytes, ferritin, lactate dehydrogenase and interleukin-6 in hospitalized patients may thus indicate the occurrence of thrombotic events [35 -37]. The severity of ALI determines the urgency and type of diagnostic evaluation and course of treatment. This vascular emergency is associated with significant morbidity and mortality and is defined as $<2$ weeks of severe hypoperfusion of the limb characterized by new or worsening symptoms featuring the 6 Ps: pain, pallor, poikilothermia, pulselessness, paresthesia and paralysis. The diagnosis is predominantly clinical and vascular imaging (duplex ultrasound, computed tomographic angiography) confirms the location and extent of arterial obstruction [38]. Therefore, imaging should be guided by resources availability and patient stability and should not delay therapeutic management, especially in hypoxemic COVID-19 patients whose transport can be a real challenge. Since timely and appropriate therapeutic anticoagulation is crucial when it comes to limb salvage and overall survival [6], all our patients received bolus followed by continuous infusion of intravenous unfractionated heparin (UFH). It is suggested that heparin efficacy is related to both its anticoagulant and anti-inflammatory properties of inhibiting several chemokines and complement and its antiviral properties of reducing viral binding through its action on the virus' spike protein [39]. However, heparin efficiency may be impaired by a number of coagulation abnormalities observed in COVID-19 patients, such as heparin resistance [40, 41] or heparin-induced thrombocytopenia. The difficulty to achieve the target activated cephalin time (ACT) when treating with UFH have been observed in our patients and thrombotic events requiring re interventions occurred in two cases despite apparently adequate anticoagulation on biology. In this highly inflammatory context, the assessment of ACT or aPTT may be not reliable since it may not reflect the real anti-Xa activity. Intervention decision in COVID-19 patients is conditioned by the severity of systemic illness. Similar to damage control in trauma patients, the principle of "life over limb" is justified. Because of the virus-induced hypercoagulability and despite revascularization attempts (endovascular, open surgical), poorer surgical results and higher mortality and limb loss rates are observed in severe COVID-19 patients with ALI [5, 6, 42]. Following intervention, all our patients were maintained on therapeutic anticoagulation and an antiplatelet agent (Asprin) to reduce incidence of recurrent ischemic events. Out of the five operated patients, two required re-intervention because of a recurrent thrombotic occlusion within the first 48 hours. Bellosta et al have concluded that prolonged 
systemic heparin might improve surgical treatment efficacy, limb salvage, and overall survival [6] but additional data on anticoagulation management for COVID-19 related ALI are needed and even anticipated [43]. In our case series, prognosis was generally poor and seems largely driven by both the overall physiologic condition at presentation and the impact of COVID-19 which induced coagulopathy severity. Non survivals had higher SOFA score and required more organ support and reinterventions. Among COVID-19 patients who develop ALI, mortality rates are as high as $50 \%$ and may be higher among ICU patients [5, 6, 23, 24]. Several studies have reported that $\mathrm{D}$-dimer levels were significantly associated with poor prognosis [37, 44, 45]. While each facility has developed guidelines and protocols for prophylactic and therapeutic anticoagulation, based or not on D-dimer levels, optimal management is still evolving rapidly as we continually acquire new insights into the disease physiopathology. ICU COVID-19 patients being at higher thromboembolic risk, our local consensus includes both a therapeutic dose of anticoagulation and anti-aggregation in the absence of obvious contraindications. The risk of hemorrhage seems no significant compared to the thrombotic risk but further anticoagulation focused studies with detailed hematological monitoring are needed to avoid a one-size-fits-all anticoagulation management. Lastly, this study has several limitations due to its retrospective and monocentric nature but adds to the previous accumulating data while raising awareness towards the poor prognosis of COVID-19 thrombosis and the challenge facing clinicians while managing this condition.

\section{CONCLUSION}

Arterial thromboembolic complications carry devastating consequences of limb loss, multiorgan dysfunction and death. ALI in COVID-19 patients is a challenging life-threatening vascular emergency that requires appropriate multidisciplinary management (intensivists, anesthesiologists, vascular surgeons and interventionists, radiologists, haematologists...) and further studies focused on anticoagulation.

\section{CONFLICT OF INTEREST:}

None.

\section{ACKNOWLEDGEMENT:}

We would like to express our gratitude and appreciation to the whole COVID-19 ICU team of our department.

\section{REFERENCES}

1. Leisman DE, Deutschman CS, Legrand M. Facing COVID-19 in the ICU: vascular dysfunction, thrombosis, and dysregulated inflammation. Intensive Care Med. 2020 Jun; 46(6):1105-1108.

2. Labò N, Ohnuki H, Tosato G. Vasculopathy and Coagulopathy Associated with SARS-CoV-2 Infection. Cells. 2020 Jun 30;9(7):1583.

3. Helms J, Tacquard C, Severac F, Leonard-Lorant I, Ohana M, Delabranche X, Merdji H, Clere-Jehl R, Schenck M, Fagot Gandet F, Fafi-Kremer S, Castelain V, Schneider F, Grunebaum L, AnglésCano E, Sattler L, Mertes PM, Meziani F; CRICS TRIGGERSEP Group (Clinical Research in Intensive Care and Sepsis Trial Group for Global Evaluation and Research in Sepsis). High risk of thrombosis in patients with severe SARS-CoV-2 infection: a multicenter prospective cohort study. Intensive Care Med. 2020 Jun;46(6):1089-1098.

4. Klok FA, Kruip MJHA, van der Meer NJM, Arbous MS, Gommers DAMPJ, Kant KM, Kaptein FHJ, van Paassen J, Stals MAM, Huisman MV, Endeman H. Incidence of thrombotic complications in critically ill ICU patients with COVID-19. Thromb Res. 2020 Jul;191:145-147.

5. Goldman IA, Ye K, Scheinfeld MH. Lower-extremity Arterial Thrombosis Associated with COVID-19 Is Characterized by Greater Thrombus Burden and Increased Rate of Amputation and Death. Radiology. 2020 Nov;297(2):E263-E269.

6. Bellosta R, Luzzani L, Natalini G, Pegorer MA, Attisani L, Cossu LG, Ferrandina C, Fossati A, Conti E, Bush RL, Piffaretti G. Acute limb ischemia in patients with COVID-19 pneumonia. J Vasc Surg. 2020; 72 (6):1864-1872.

7. Kashi M, Jacquin A, Dakhil B, et al. Severe arterial thrombosis associated with Covid-19 infection. Thromb Res. 2020; 192:75-77.

8. Singh B, Aly R, Kaur P, Gupta S, Vasudev R, Virk HS, Shamoon F, Bikkina M. COVID-19 Infection and Arterial Thrombosis: Report of Three Cases. Ann Vasc Surg. 2021 Jan;70:314-317

9. Perini P, Nabulsi B, Massoni CB, Azzarone M, Freyrie A. Acute limb ischaemia in two young, nonatherosclerotic patients with COVID-19. Lancet. 2020 May 16; 395(10236): 1546.

10. Putko RM, Bedrin MD, Clark DM, Piscoya AS, Dunn JC, Nesti LJ. SARS-CoV-2 and limb ischemia: A systematic review. J Clin Orthop Trauma. 2021;12(1):194-199.

11. Sánchez JB, Cuipal Alcalde JD, Ramos Isidro R, Luna CZ, Cubas WS, Coaguila Charres A, Gutiérrez JE, Ochoa JD, Arias PF. Acute Limb Ischemia in a Peruvian Cohort Infected by COVID-19. Ann Vasc Surg. 2020 Dec 31:S0890-5096 (20) 31102-X.

12. Lari E, Lari A, AlQinai S, Abdulrasoul M, AlSafran S, Ameer A, Al-Sabah S. Severe ischemic complications in Covid-19-A case series. Int J Surg Case Rep. 2020;75:131-135.

13. Anwar S, Acharya S, Shabih S, Khabut A. Acute Limb Ischemia in COVID-19 Disease: A Mysterious Coagulopathy. Cureus. 2020;12 (7):e9167. 
14. Demir KK, Simard C, Lipes J, Yang SS. Life and Limb: a Case of COVID-19-Associated Multisystem Thrombosis and Review of the Literature. J Gen Intern Med. 2021 Jan 5:1-5.

15. Topcu AC, Ariturk C, Yilmaz E. Acute limb ischemia in a COVID-19 patient. Thrombosis Update. 2021;2:100031.

16. Warrior K, Chung PA, Ahmed N, Soult MC, Simpson KP. Acute Limb Ischemia Due to Arterial Thrombosis Associated With Coronavirus Disease 2019. Crit Care Explor. 2020 Jun; 2(6): e0140.

17. Wengerter SP, Wengerter KR, Masoudpoor H, Sagarwala A, Karim O, Rao N, Gillen J, Choi HM, Bernik T, Schwartz ML. Acute aortoiliac and infrainguinal arterial thrombotic events in four patients diagnosed with the novel coronavirus 2019. J Vasc Surg Cases Innov Tech. 2020 Dec;6(4):698702.

18. Levolger S, Bokkers RPH, Wille J, Kropman RHJ, de Vries JPM. Arterial thrombotic complications in COVID-19 patients. J Vasc Surg Cases Innov Tech. 2020 Sep;6(3):454-459.

19. Hasan SA, Haque A, Nazir F. Acute Limb Ischemia: A Rare Complication of COVID-19. Cureus. 2020 Nov 15;12(11):e11488.

20. Schweblin C, Hachulla AL, Roffi M, Glauser F. Delayed manifestation of COVID-19 presenting as lower extremity multilevel arterial thrombosis: a case report. Eur Heart J Case Rep. 2020 Nov 19;4(6):1-4.

21. Soares RA, Vedovello RS, Medeiros SCG, Nunes CZ, Sian CA, Jorge PDM. COVID-19 diagnosis in a patient with critical limb ischemia: complications and clinical outcomes. J Vasc Bras. 2020;19:e20200071.

22. Etkin Y, Conway AM, Silpe J, et al. Acute Arterial Thromboembolism in Patients with COVID-19 in the New York City Area. Ann Vasc Surg 2021; 70:290.

23. Indes JE, Koleilat I, Hatch AN, et al. Early experience with arterial thromboembolic complications in patients with COVID-19. J Vasc Surg. 2021;73(2):381-389.e1.

24. Ilonzo N, Rao A, Safir S, Vouyouka A, Phair J, Baldwin M, Ting W, Soundararajan K, Han D, Tadros R, Marin M, Faries P. Acute thrombotic manifestations of coronavirus disease 2019 infection: Experience at a large New York City health care system. J Vasc Surg. 2020 Sep 1:S07415214(20)31922-4.

25. Thompson O, Pierce D, Whang D, et al. Acute limb ischemia as sole initial manifestation of SARS-CoV2 infection. J Vasc Surg Cases Innov Tech 2020; 6:511.

26. Kaur P, Posimreddy S, Singh B, et al. COVID-19 Presenting as Acute Limb Ischaemia. Eur J Case Rep Intern Med 2020; 7:001724.

27. Essa RA and Ahmed SK. Case Report: Acute lower limb ischemia in a recovered COVID-19 patient [version 1; peer review: awaiting peer review]. F1000Research 2020, 9:1253.

28. Veerasuri S, Kulkarni SR, Wilson WR, Paravastu SCV. Bilateral Acute Lower Limb Ischemia Secondary to COVID-19. Vasc Endovascular Surg 2021; 55:196.

29. Galanis N, Stavraka C, Agathangelidis F, Petsatodis E, Giankoulof C, Givissis P. Coagulopathy in
COVID-19 infection: a case of acute upper limb ischemia. J Surg Case Rep. 2020 Jul 2;2020(6):rjaa204.

30. Hanif M, Ali MJ, Haider MA, et al. Acute Upper Limb Ischemia Due To Arterial Thrombosis in a Mild COVID-19 Patient: A Case Report. Cureus 2020; 12:e10349.

31. Shao T, In-Bok Lee C, Jabori S, Rey J, Duran ER, Kang N. Acute upper limb ischemia as the first manifestation in a patient with COVID-19. J Vasc Surg Cases Innov Tech. 2020 Dec;6(4):674-677.

32. Schultz K, Wolf JM. Digital Ischemia in COVID-19 Patients: Case Report. J Hand Surg Am 2020; 45:518.

33. Giacomelli E, Dorigo W, Fargion A, et al. Acute Thrombosis of an Aortic Prosthetic Graft in a Patient with Severe COVID-19-Related Pneumonia. Ann Vasc Surg 2020; 66:8

34. Varga Z, Flammer AJ, Steiger P, et al. Endothelial cell infection and endotheliitis in COVID-19. Lancet 2020;395: 1417e8.

35. Colling ME, Kanthi Y. COVID-19-associated coagulopathy: An exploration of mechanisms. Vasc Med 2020; 25:471.

36. Fan BE, Chia YW, Sum CLL, et al. Global haemostatic tests in rapid diagnosis and management of COVID-19 associated coagulopathy in acute limb ischaemia. J Thromb Thrombolysis 2020; 50:292

37. Terpos E, Ntanasis-Stathopoulos I, Elalamy I, et al. Hematological findings and complications of COVID-19. Am J Hematol 2020; 95:834.

38. Creager MA, Kaufman JA, Conte MS. Clinical practice. Acute limb ischemia. N Engl J Med 2012; 366:2198.

39. Mycroft-West C, Su D, Elli S, et al. The 2019 coronavirus (SARS-CoV-2) surface protein (Spike) $\mathrm{S} 1$ receptor binding domain undergoes conformational change upon heparin binding. bioRxiv. 2020. doi: https://doi.org/10.1101/2020.04.29.068486.

40. Beun R, Kusadasi N, Sikma M, et al. Thromboembolic events and apparent heparin resistance in patients infected with SARS-CoV-2. Int J Lab Hematol 2020;42:19e20.

41. Baccellieri D, Bilman V, Apruzzi L, et al. A Case of Covid-19 Patient with Acute Limb Ischemia and Heparin Resistance. Ann Vasc Surg 2020; 68:88.

42. Lewis CT, Dayal R, Sundaram V, Chhaya V. Revascularization Outcomes in COVID-19 Patients With Acute Limb Ischemia. J Vasc Surg. 2020;72(5): 374

43. D'Oria M, Mills JL Sr, Cohnert T, et al. The "Vascular Surgery COVID-19 Collaborative" (VASCC). Eur J Vasc Endovasc Surg 2020; 60:489.

44. Vidali S, Morosetti D, Cossu E, et al. D-dimer as an indicator of prognosis in SARS-CoV-2 infection: a systematic review. ERJ Open Res. 2020; 6:00260.

45. Tang N, Li D,Wang X, et al. Abnormal coagulation parameters are associated with poor prognosis in patients with novel coronavirus pneumonia. J Thromb Haemost 2020;18:844e 